\title{
A noção fenomenológica de existência e as práticas psicológicas clínicas
}

\section{The phenomenological notion of existence and psychological clinical practices}

\author{
Roberto Novaes de SÁ \\ Carmem Lúcia Brito Tavares BARRETO²
}

\begin{abstract}
Resumo
Este artigo apresenta o modo de ser do homem como "existência", tal como elaborado por Heidegger em "Ser e Tempo", como uma das contribuições mais fundamentais da fenomenologia para a psicologia clínica. A noção de "existência", também relacionada às de "ser-aí" (Dasein) e "ser-no-mundo", é compreendida como abertura originária ao ser dos entes, como pré-compreensão do ser enquanto tal, vinculada à condição de "estar-lançada" em uma facticidade temporal. Entende-se que a noção heideggeriana de "existência" demarca uma atitude clínica nitidamente diferenciada e oferece novas possibilidades de tematização dos fenômenos psicológicos e da prática clínica. As práticas psicológicas clínicas de perspectiva fenomenológica existencial, ao tomarem a experiência de si e do outro como "ser-no-mundo-com", apresentam-se como espaços de cuidado/desvelamento dessas possibilidades de "ser-com" e não de um sujeito intrapsíquico.
\end{abstract}

Unitermos: Existência. Fenomenologia. Práticas psicológicas clínicas.

\begin{abstract}
This essay presents man's way of being as "existence", as formulated by Martin Heidegger in Being and Time, as one of the most fundamental contributions of Phenomenology to Clinical Psychology. The notion of "existence", also related to "being-there" (Dasein) and "being-in-theworld", is understood as the origin of the essence of beings, i.e., a pre-understanding of being itself, linked to the human condition of 'beingthrown 'into a temporal facticity. It is understood that the heideggerian notion of "existence" defines a clearly distinctive clinical attitude and presents new possibilities for thematizing psychological phenomena and clinical practices. Psychological practices of a phenomenological and existential perspective assume the experience of self and others as an experience of "being-in-the-world-with". In this way, they should be understood as spaces for taking care of those possibilities of "being-with" rather than taking care of an intrapsychic subject.
\end{abstract}

Uniterms: Existence. Phenomenology. Clinical psychology practices.

Uma das contribuições mais fundamentais da fenomenologia para a psicologia é a compreensão do modo de ser do homem como "existência", tal como foi elaborado por Heidegger (1927/1989) em sua obra"Ser e Tempo". Embora de uso corrente nas chamadas psicologias fenomenológico-existenciais e nas correntes

$\boldsymbol{\nabla \nabla \nabla \nabla}$

1 Universidade Federal Fluminense, Programa de Pós-Graduação em Psicologia. Niterói, RJ, Brasil.

2 Universidade Católica de Pernambuco, Programa de Pós-Graduação em Psicologia Clínica. R. Do Príncipe, 526, Boa Vista, 50090-900, Recife, PE, Brasil. Correspondência para/Correspondence to: C.L.B.T. BARRETO. E-mail: <carmemluciabarreto@hotmail.com>. 
humanistas, e mesmo tendo ganhado estatuto conceitual em outros discursos clínicos, a noção de "existência" carece ser permanentemente problematizada com relação a sua compreensão própria, pois a radicalidade que a torna um diferencial na história recente das ideias filosóficas e psicológicas tende a ser facilmente perdida em prol de um nivelamento com as concepções naturalistas mais usuais sobre o ser do homem.

Este artigo tem como objetivo principal refletir sobre esse nivelamento conceitual e esclarecer a compreensão radical da noção de "existência", possibilitando pensar o direcionamento próprio de uma prática psicológica clínica a partir dos pressupostos da Analítica da Existencial proposta por Heidegger. Desse modo, busca-se contribuir para apontar as limitações e as possíveis inadequações da aplicação de concepções decorrentes da perspectiva científico-natural à psicologia, com uma consideração insuficiente à especificidade do modo de ser do homem. A existência exige uma reflexão própria, o que não significa uma oposição reativa ao saber científico, mas "chegar a uma relação refletida com a ciência e verdadeiramente meditar sobre seus limites"(Heidegger, 2001, p.45).

\section{A noção fenomenológica de existência}

A noção de "existência"só pode ser devidamente compreendida à luz de uma atitude ou modo específico de atenção, que não é aquele em que nos encontramos naturalmente na vida cotidiana, nem mesmo quando empregamos a racionalidade científica para abordar a realidade. A expressão husserliana "atitude natural" denomina nossa tendência de tomar todas as coisas que encontramos no mundo como se já sempre estivessem dadas aí, indiferentes à nossa relação de sentido com elas. O próprio sujeito é tomado como algo dado dentro de um mundo que lhe é anterior. A diferença entre o modo de ser do sujeito e o das coisas restringe-se, a partir de uma ontologia cartesiana, em ter ou não uma natureza extensa, mas, para aquém dessa diferença, ambos são ainda simplesmente dados dentro do mundo. Colocar-se numa perspectiva fenomenológica é suspender essa suposição "natural" de uma realidade "em si", realizar uma epoché, retornando para as coisas apenas enquanto dadas à experiência; é envolver-se em um modo de atenção em que experienciamos com to- da evidência que o mais "concreto" não é essa suposta "realidade-em-si" do mundo, o mais "concreto"é sempre o próprio acontecimento imanente da "experiência" enquanto dinâmica constitutiva de sujeito e objeto. 0 conhecimento do mundo nos inclui e dá-se a partir do nosso ser-no-mundo. Assim, na noção de mundo "não se trata da natureza enquanto realidade objetiva (estudada pela ciência positivista), mas do mundo que se dá na relação, que se mostra como fenômeno primeiro e que pode ser depois elaborado pelo pensamento" (Amatuzzi, 2009, p.95).

Para uma aproximação compreensiva desse plano de constituição dos entes, que não é, ele mesmo, ente algum, pode-se recorrer a um koan da tradição Zen Budista, conhecido e evocado por Heidegger em um diálogo ocorrido em 1958, em Freiburg, com o filósofo japonês da escola de Kioto e mestre zen da tradição Rinzai, Sh. Hisamatsu (Saviani, 2005). Trata-se de uma pergunta que, ao invés de levar a uma resposta específica, visa deslocar a perspectiva de compreensão do interrogado. O mestre bate palmas e pergunta ao discípulo: "Qual é o som que surge de apenas uma das mãos?" (Samten, 2001, p.41). Quando se bate a mão contra algo como uma mesa, um livro ou um copo de vidro, identificam-se diferentes sons que são atribuídos aos próprios objetos. Dizemos: este é o som da madeira, este do vidro, etc. Quando batemos uma mão espalmada contra outra, de qual das mãos seria o som, sendo ambas iguais? Percebe-se então que o som não é atributo de um objeto, surge da relação. Ampliando essa reflexão, pode-se ver que todas as atribuições de qualidades que fazemos às coisas, como se fossem características inerentes a uma substância, são frutos de uma simplificação ingênua. Antes de qualquer substância extensa ou psíquica, inferida como suporte de qualidades, há uma dinâmica de "originação interdependente"entre sujeito e objeto.

Podemos aproximar, com as devidas reservas, essa concepção budista de originação interdependente e a compreensão heideggeriana sobre a cooriginariedade de homem e mundo. Essa abertura originária de sentido, jamais objetivável como algo dentro de um mundo pré-existente, é aquilo que Heidegger denominou como "existência", "ser-aí" (Da-sein) ou ser-no-mundo. O existir humano não pode ser considerado como algo simplesmente presente e encerrado em si; "ao 
contrário, esse existir consiste em meras possibilidades de apreensão que apontam ao que lhe fala e o encontra e que não podem ser apreendidas pela visão e pelo tato" (Heidegger, 2001, p.33). Existência, portanto, não é o fato bruto e indiferenciado de ser, como oposição metafísica ao não ser, significa uma abertura originária ao ser dos entes, enquanto pré-compreensão do ser enquanto tal. Desse modo, podemos interpretar a"existência" como pura possibilidade no horizonte intransponível da temporalidade. Isso não se confunde, de modo algum, com a reversão de uma postura realista para um idealismo, conforme certas interpretações da fenomenologia estimuladas, segundo Barreto (2006), por algumas formulações do próprio Husserl."Idealidades", como concebidas pelos idealismos filosóficos, não são menos "naturais" que "empiricidades". Isto é, objetos ideais, embora não extensos, são ainda concebidos como "coisas-em-si", quer de natureza espiritual, racional ou psicológica. Para uma atitude fenomenológico-hermenêutica, os objetos ideais não são nem mais nem menos reais que os objetos empíricos, são apenas diferentes modos de ser daquilo que se dá à experiência.

Esse deslocamento da compreensão não se reduz a um mero movimento do intelecto e isso fica óbvio no vocabulário fenomenológico de "Ser e Tempo". Heidegger designa como "afinação" (Stimmung) ou "disposição" (Befindlichkeit) o modo como o homem, enquanto abertura de sentido, "sintoniza" os entes que Ihe vêm ao encontro no mundo. Assim,"o homem pode se relacionar de diferentes modos com os entes que se apresentam a ele [...] mesmo a indiferença é um modo de relação"(Sá \& Mattar, 2008, p.198). Para ele, a disposição privilegiada, a partir da qual o homem pode apreender seu modo de ser próprio enquanto "existência," é a angústia. Ela remete o homem à sua singularidade, ao seu próprio poder-ser-no-mundo. Tem, portanto, uma função liberadora, podendo arrastar o homem para a propriedade de seu ser enquanto possibilidade de ser, afastando-o da perspectiva impessoal e objetivante da ocupação cotidiana. Há na angústia um sentimento de estranheza, retirando o homem da aparente segurança e da experiência de bem-estar proveniente do nivelamento de seu ser a partir daquilo com que se ocupa no mundo. Pela disposição da angústia, o homem é "retirado da publicidade e da decadência e Ihe são reveladas a propriedade e a impropriedade como possibilidades de seu ser"(Vásquez, 1999, p.152). Quando habitada sem os subterfúgios da impessoalidade mediana, a angústia "[...] desempenha um papel similar à Epoche de Husserl, despindo as coisas de sua significação habitual" (Inwood, 2002, p.95).

Diante dessas considerações, podemos entender o equívoco de alguns nivelamentos correntemente efetuados com a noção de "existência". O mais comum, talvez devido a certa má compreensão do existencialismo francês, consiste na mera inversão da tradição metafísica "essencialista". Pensa-se que a valorização da existência concreta, factual, encarnada, é apenas uma subordinação do "espiritual" ao "material", do "eterno" ao "histórico", mas subsiste um resíduo de "simplesmente dado" nesse polo oposto às essências que seria a "existência concreta". A condição de "estar-lançada" da existência, sua facticidade temporal, incluída aí toda a corporeidade, jamais se confunde com um contexto simplesmente dado, no qual se encontra um sujeito livre apenas para interpretar ao seu modo essas condições dadas. A facticidade jamais pode ser acrescentada à existência, nem, muito menos, a liberdade é algo acrescentado a um estar lançado fáctico. Enquanto projeto (Entwurf), a existência já é sempre descentrada a partir de sua facticidade; a liberdade não se opõe ao ser-situado-junto-ao-mundo, antes Ihe é condição de possibilidade. Da mesma forma, a historicidade da existência não pode significar o estar meramente"no tempo", sendo determinada por eventos temporais.

A objetivação do tempo e da história como uma "moldura" na qual a existência sempre se encontra já é fruto de uma distração da atenção fenomenológica, que faz com que retornemos a uma compreensão natural da existência como algo dado dentro de um mundo. Assim como existência é ser-no-mundo e não algo dentro do mundo, a temporalidade existencial jamais significa ser dentro do tempo. "Dentro"indica uma relação de justaposição de "coisas" simplesmente dadas num determinado lugar do espaço. Ao contrário, ser-no-mundo refere-se a um fenômeno de unidade constituído ontologicamente pelos "existenciais". Assim, ser-no-mundo, ser junto ao mundo é um existencial, um modo de ser-em, que só pode "tocar" um ente se pelo seu modo de ser originário já Ihe houver sido descoberto um mundo. Heidegger afirma em "Ser e Tempo" que "o ser-em é, pois, a expressão formal e existencial 
do ser da pre-sença (Dasein) que possui a constituição essencial de ser-no-mundo"(Heidegger, 1927/1989, p.92). Assim como a existência é ser-no-mundo e não algo dentro do mundo, a temporalidade existencial jamais significa ser dentro do tempo. Se "existir"é ser no mundo como abertura de sentido em que já sempre nos vêm ao encontro os entes, existir é temporalizar e espacializar. Nessa direção, a "existência"enquanto "ser-aí"é a clareira do ser, a abertura na qual o ente destituído de mundo poder vir ao encontro e revelar-se em seu ser, vir à luz. 0 homem é um ente voltado para "fora" (ec-sistência), cuja essência consiste em ter que compreender a si mesmo, neste fora, como possibilidade de ser ou não ser ele mesmo.

Outro nivelamento comum é aquele que toma a noção de ser-no-mundo como uma simples valorização do caráter relacional, holístico, da condição humana, mas fazendo subsistir ainda um mundo simplesmente dado no interior do qual o homem se encontra sempre em uma rede de relações constitutivas de sua existência. Para esse tipo de interpretação, nomear o homem como ser-no-mundo seria análogo à afirmação de que ele é essencialmente um ser social, intersubjetivamente constituído. Por mais dinâmica e complexa que seja a representação desse modo de subjetividade holisticamente produzida, trata-se ainda de uma objetivação que não traduz a experiência radical do nosso "si-mesmo"como mero "poder-ser", abertura originária de sentido; condição ontológica, não objetivável, de qualquer objetivação. Tais representações objetivantes seguem a orientação da episteme hegemônica da modernidade ocidental que mapeou e sinalizou o caminho das ciências modernas. Inserindo-se nessa tradição metafísica de conhecimento, que só pode tomar como ente digno de interesse o que pode ser objetivado, a psicologia constituiu-se como ciência: buscou a plena elucidação e controle das realizações da existência e não considerou a condição ontológica do existir humano fecundado pelo mistério do ser e do tempo.

No entanto, não queremos com essas observações impugnar ou desvalorizar as influências que a noção heideggeriana de "existência" exerceu sobre as diversas áreas e correntes da psicologia, apenas ressaltar que, dissociada de uma atitude fenomenológica, tal 392 noção perde seu sentido ontológico próprio. A noção de "existência" aponta para o modo de ser do homem como abertura originária ao ser, possibilitando uma reflexão sobre a experiência clínica orientada pelos pressupostos ontológicos, não metafísicos, referentes à experiência humana, elaborados pela analítica existencial heideggeriana.

\section{Práticas psicológicas clínicas}

Com relação às práticas psicológicas, as consequências dessa concepção do ser do homem como "existência" demarcam uma atitude clínica nitidamente diferenciada, que poderíamos, resumidamente, sistematizar em três aspectos estritamente articulados entre si: o abandono de qualquer redução do humano a dimensões meramente orgânicas, psicológicas ou sociais, naturalmente compreendidas, isto é, o abandono de qualquer cientificismo objetivante do sofrimento existencial; a suspensão de toda postura técnica e voluntarista, em que o terapeuta se coloca no lugar daquele que conduz a dinâmica do processo clínico a partir de suas representações técnico-conceituais sobre a existência do paciente ou a partir de seu desejo pessoal de impor mudanças; o exercício da atenção e do cuidado livre de expectativas, em que o outro é convidado a uma lembrança de si como pura "existência" para, a partir daí, perspectivar seus limites e suas possibilidades mais próprias e singulares.

Desse modo, a hermenêutica, assumida na analítica existencial como situação constitutiva da existência, pode oferecer, a partir de seus pressupostos ontológicos, novas possibilidades de tematização dos fenômenos psicológicos e da atitude clínica. Precisamente, a adoção desses pressupostos exige o abandono de toda tentação de transpor para o âmbito da clínica os elementos essenciais do método cientifico-natural: redução à objetividade conceitual, quantificação e mensuração.

Considerando os três aspectos mencionados mais acima para demarcar uma clínica de compreensão fenomenológica existencial, pode-se entender a atitude clínica como possibilidade do cuidado do psicólogo implicado no movimento de atenção ao cliente como existência, acompanhando-o na tarefa de apropriar-se daquilo que sabe pré-ontologicamente, possibilitando, na sua situação concreta e totalmente singular, que se compreenda e assuma o que ele é, em seu estar-lançado, 
e o que pode ser. É mediante essa apropriação narrativa da sua conjuntura e das suas maneiras de sentir-se e de responder praticamente a ela, que o cliente chegará a compreender-se como aquele cujo ser está sempre em jogo no conjunto das circunstâncias existenciais que Ihe são tematicamente abertas na interlocução clínica. Dessa forma, pode compreender-se e aceitar-se, sejam quais forem os seus sofrimentos, como responsável, no sentido de responder e apropriar-se das solicitações concretas da vida. Longe de uma culpabilização paralisante, essa responsabilidade é uma ampliação da liberdade (Barreto, 2006).

Assim, a atitude clínica mostra-se intimamente associada à própria atitude fenomenológica de suspensão das objetivações da existência e abertura à experiência de si e do outro como ser-no-mundo-com, como cuidado ontológico, condição de possibilidade para o acontecimento de uma transformação não produzida tecnicamente, mas emergente em forma de reflexão sobre o sentido. Esse novo"olhar", essa quebra do habitual, pode ter início a partir dos estranhamentos ecoantes nas brechas de nossa existência superficial via"acontecimentos" que, ao provocarem ruptura e transição, destroçam e fundam horizontes de mundo, se e quando cedemos ao apelo dos traços fundantes e constitutivos (ontológicos) do nosso ser si-mesmo próprio e singular. Tal rompimento possibilita mudança e transformação ao abrir a crise que dissolve e leva o "aí" a constituir-se outro.

Nesse contexto, a atitude fenomenológica, além de constituir-se como uma das dimensões fundamentais da prática psicológica clínica, apresenta-se também como uma atitude "que une tantos pesquisadores, não somente como modo de acesso ao mundo ou forma de pesquisa para compreensão do objeto, mas fundamentalmente como uma ontologia" (Ewald, 2008, p.150). Não se apreende a fenomenalidade das ciências humanas pela interpretação própria às ciências naturais; ela exige outra possibilidade de interpretação alcançável por meio do rigor descritivo interpretativo - deixar ver e fazer ver - via fenomenologia, o que implica descrições compartilháveis sobre os fenômenos que permeiam as situações singulares. Nessa direção, a descrição fenomenológica dos fenômenos clínicos não se pode pretender universalizante, com generalizações de comportamentos singulares, pois a singularidade da existência é incontornável.
Acompanhar o cliente nessa tarefa significa auxiliá-lo a tornar explícito para si mesmo o sentido de suas experiências: dores, alegrias e de suas possibilidades negadas. Nessa compreensão, não há nenhum direcionamento, mas a desconstrução das meras opiniões ditadas pelo falatório do impessoal e a quebra das habitualidades abrem fissuras que deixam entrever possíveis mudanças, transformando o acontecer clínico em experiência apropriada e tematizada, constituída por "aceitar simplesmente aquilo que se mostra no fenômeno do tornar presente e nada mais"(Heidegger, 2001, p.101).

Assim compreendida, a ação clínica apresenta-se como escuta que chama o "dizer" (zeigen), compreendido como deixar ver, e prepara a situação para que ele possa acontecer como abertura para outras possibilidades de ser. Esta"seria a tarefa do terapeuta existencial: resgatar o homem singular que se encontra perdido no geral" (Feijoo, 2008, p.317).

Pensamos que a maior dificuldade em conceber desse modo a atitude clínica é a de não fazê-la recair em uma nova "técnica" que venha a se opor e substituir as outras. Assim como a "atitude fenomenológica" não substitui a "atitude natural", no sentido de negar a experiência através dela realizada, mas apenas suspende sua pretensão de "verdade natural" para permanecer no plano do sentido, também uma postura clínica fenomenológica não deve pretender excluir os comportamentos terapêuticos "naturais" de cuidado substitutivo, isto é, as prescrições técnicas e os conselhos pessoais, e, sim, retirar desses comportamentos seu caráter de fundamento da clínica, subordinando-os a uma atenção que busca sustentar a lembrança da dinâmica de realização terapêutica enquanto possibilidade ôntica da nossa condição ontológica de ser-no-mundo-com-o-outro.

Assim compreendida, a atitude clínica transita entre o ôntico e o ontológico e tem como direção o desvelamento do "poder-ser" por meio do apropriar-se da propriedade e da impropriedade. A atitude clínica parte da disposição afetiva da angústia como abertura privilegiada para uma compreensão própria da existência, mas aponta também a possibilidade de um existir sereno, antecipatório do ser-para-a-morte e aberto ao mistério (Barreto, 2006). De acordo com Heidegger, "a serenidade em relação às coisas e a abertura ao segredo são inseparáveis. Concedem-nos a possibilidade de estarmos no mundo de um modo completamente diferente"(Heidegger, 1959, p. 25). 


\section{Considerações Finais}

Embora o essencial da fenomenologia esteja aquém de suas institucionalizações, enquanto correntes do saber filosófico e psicológico, e conduza para possibilidades da experiência humana cujas ressonâncias nos chegam a partir das origens imemoriais das tradições filosóficas e sapienciais do pensamento, sua atualidade para a psicologia e, particularmente, para o campo das práticas psicológicas clínicas não deve ser subestimada.

No mundo atual, as vivências de sofrimento existencial, endereçadas à clínica psicoterápica, cada vez mais estão relacionadas ao nivelamento histórico dos sentidos ao que se enquadra no projeto global de controle, exploração e consumo. As produções contemporâneas de novos modos de subjetividades demandam das práticas psicológicas clínicas uma permanente reflexão e rearticulação de suas estratégias. Neste contexto, para que a psicoterapia possa se constituir em um espaço de cuidado e abertura a outros modos de existir, ela não pode permanecer acriticamente subordinada a esse mesmo horizonte histórico de redução de sentido (Sá, 2009, p.73).

O problema das crises e conflitos gerados pelas experiências das diferenças e alteridades, bem como sua negação na contemporaneidade, está no centro dessas preocupações críticas e transformações dos saberes e das práticas psicológicas. Cada vez mais são tematizadas as tensões entre estratégias de regulação e de emancipação sociais em jogo desde as origens do projeto histórico da época moderna.

Nesse horizonte de transformações da psicologia atual, Sá (2009) aponta que a fenomenologia traz contribuições fundamentais que estão presentes desde as preocupações de Husserl (2002), com "A crise da humanidade europeia e a Filosofia", atravessam as meditações de Heidegger, quando interpela sobre as consequências da técnica moderna, e chegam às diversas análises políticas de inspiração fenomenológica de Sartre (1943/2005) e Arendt (1958/1999). Nessa vocação fenomenológica para a análise crítica do contemporâneo, sobressai a aposta de que somente através de uma consciência cada vez mais clara do papel de regulação e dominação exercido pelas institucionalizações técnico-científicas da vida cotidiana é possível que as práticas psicológicas venham a se constituir espaços de abertura e cuidado para possibilidades históricas de ser-no-mundo-com-o-outro mais plurais e emancipatórias.

\section{Referências}

Amatuzzi, M. M. (2009). Psicologia fenomenológica: uma aproximação teórica humanista. Estudos de Psicologia (Campinas), 26 (1), 93-100. doi: 10.1590/S0103166X2009 000100010.

Arendt, H. (1999). A condição humana. Rio de Janeiro: Florense Universitária. (Originalmente publicado em 1958).

Barreto, C. L. B. T. (2006). Ação clínica e os pressupostos fenomenológicos existenciais. Tese de doutorado não-publicada, Programa de Pós-Graduação em Psicologia, Universidade de São Paulo.

Ewald, P. A. (2008). Fenomenologia e existencialismo: articulando nexos, costurando sentidos. Estudos e Pesquisa em Psicologia, 8 (2), 149-165.

Feijoo, A. M. L. C. (2008). A filosofia da existência e os fundamentos da clínica fenômenológica. Estudos e Pesquisa em Psicologia, 8 (2), 309-318.

Heidegger, M. (1959). Serenidade. Lisboa: Instituto Piaget.

Heidegger, M. (1989). Ser e tempo. Petrópolis: Vozes. (Originalmente publicado em 1927).

Heidegger, M. (2001). Seminários de Zollikon. Petrópolis: Vozes.

Husserl, E. (2008). A crise da humanidade européia e a filosofia. Porto Alegre: Edipucrs.

Inwood, M. (2002). Dicionário Heidegger. Rio de Janeiro: Jorge Zahar.

Sá, R. N. (2009). Psicoterapia, cientificidade e interdisciplinaridade: a propósito de uma discussão sobre a suposta necessidade de uma regulamentação das práticas psicológicas clínicas. In H. J. L. F. Rodrigues \& A. L. Brito, (Orgs.), Ano da psicoterapia: textos geradores. Brasília: Conselho Federal de Psicologia.

Sá, R. N., \& Mattar, M. C. (2008). Os sentidos de "análise" e "analítica" no pensamento de Heidegger e suas implicações para a Psicoterapia. Estudos e Pesquisa em Psicologia, 8 (2), 191-203.

Samten, P. (2001). A jóia dos desejos. São Paulo: Fundação Petrópolis.

Sartre, J-P (2005). O Ser e o nada: ensaio de ontologia. Petrópolis: Vozes. (Originalmente publicado em 1943).

Saviani, C. (2005). El Oriente de Heidegger. Barcelona: Herder.

Vásquez, J. (1999). Angústia e desamparo numa perspectiva heideggeriana. Perspectiva Filosófica, 11 (6), 145-157.

Recebido em: 18/9/2009

Versão final reapresentada em: 12/11/2010

Aprovado em: 6/12/2010 